\title{
УРОВЕННЫИ РЕЖИМ И МИНЕРАЛИЗАЦИЯ ГРУНТОВЫХ ВОД НА МОРСКОМ БЕРЕГУ КУРОРТА ПЯРНУ
}

Уровень и химический состав грунтовых вод зависят, как известно, в основном от метеорологических условий, а на морском берегу подвержены еще и влиянию моря. Для установления дальности влияния и выявления закономерности воздействия морской воды на режим грунтовых вод нами были проведены режимные наблюдения в естественных условиях на берегу Пярнуского залива в районе курорта Пярну. Здесь у западной границы города, где падение рельефа равно примерно $1,5 \mu$ на $1 \kappa м$, в прибрежно-морских песках было пробурено пять скважин глубиной от 3 до 3,5 м по профилю, перпендикулярному к

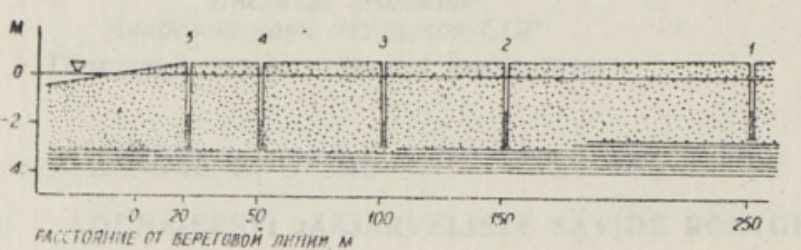

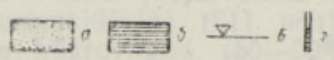

Рис. 1. Местоположенне наблюдательных скважин. Обозначения: $a$ - пески, б-ленточные глины, 8 уровень моря, 2 - скважины, рабочая часть заштрихована.

У ровенны й ре жи м грунтовых вод на исследованном профиле характеризуется двумя максимумами - весной и осенью и двумя минимумами - летом и зимой. Кривые годового хода в общих чертах повторяют друг друга (рис. 2). За нулевую отметку уровня грунтовых вод принята высота воды в скв. 5 18/X 1966 г., которая совпала с нулевым уровнем моря на гидрометеорологической станции Пярну. Определенный относительно нулевой отметки средний годовой уровень в 1967 г. составил $0,17-0,19$ и и в 1968 г. - соответственно $0-0,05$ м.

Под влиянием весеннего таяния снегов уровень грунтовых вод в скважинах поднимался и достигал максимума к концу марта - началу апреля. В 1967 г. вода в скважинах на различных расстояниях от береговой линии поднялась на $0,47-0,51, м$ выше среднего годового уровня. Пройдя через максимум, который длился 3 недели, уровень грунтовых вод скачкообразно понизился. 


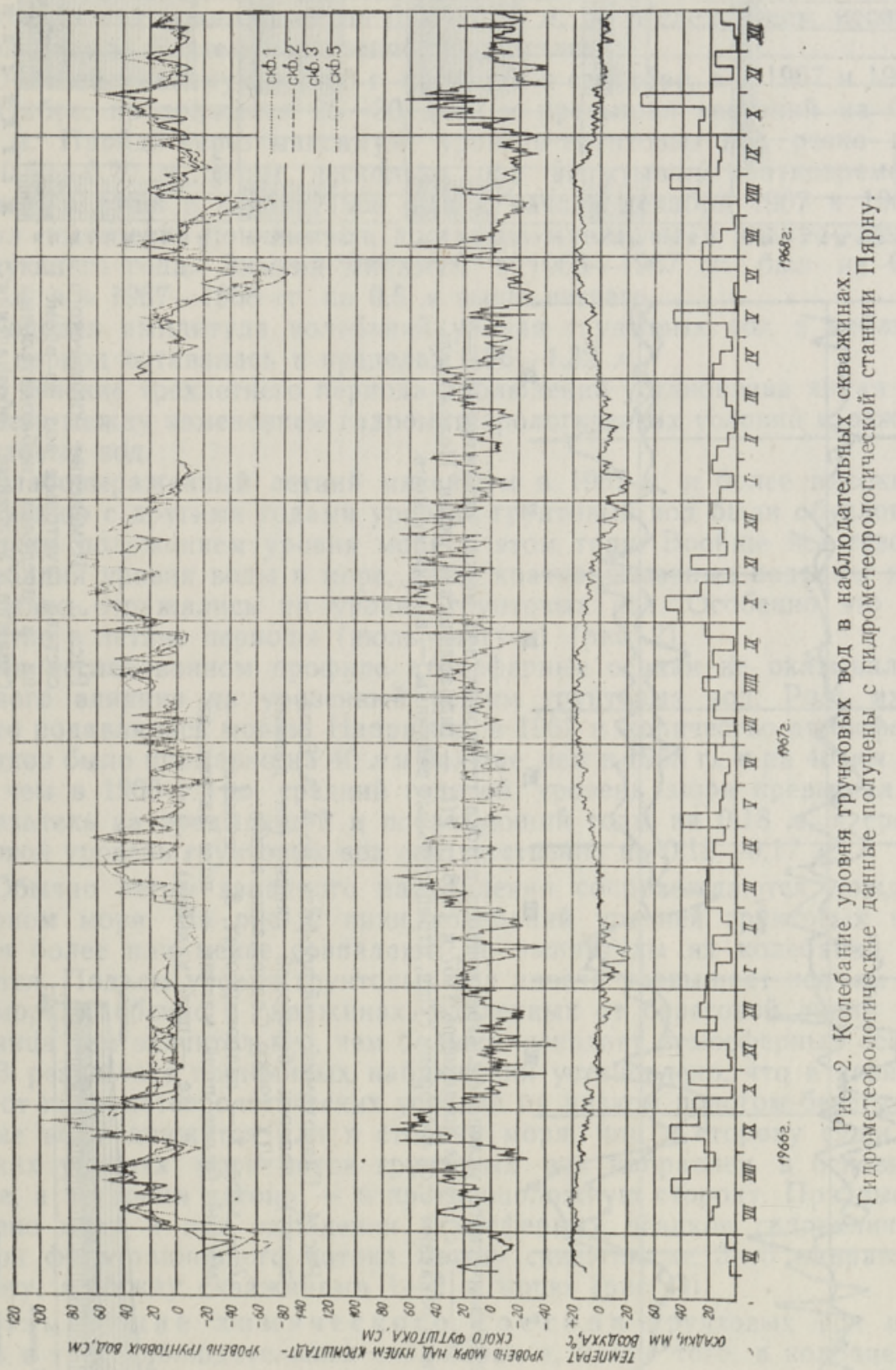



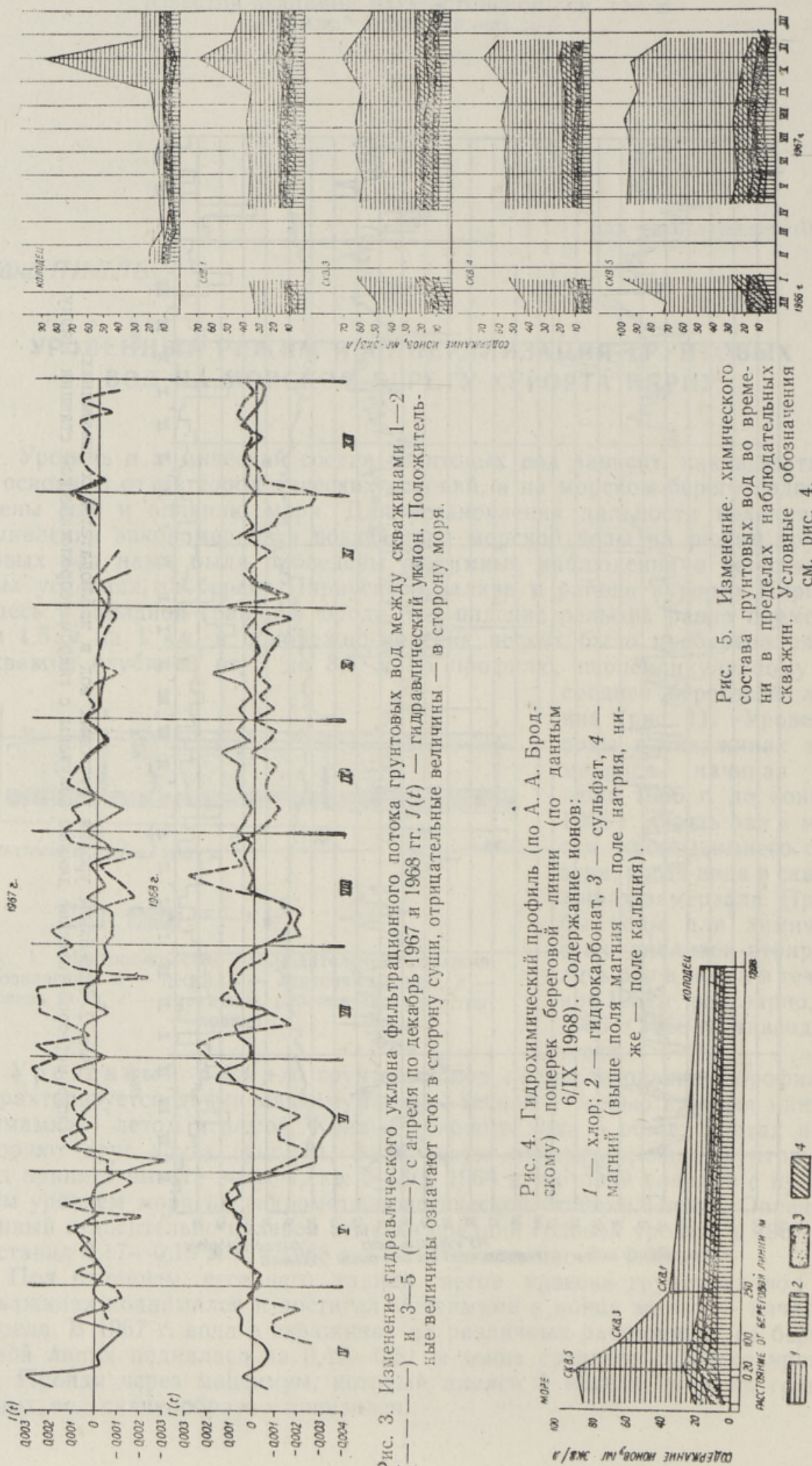

i

1

폴

和响

ํㅗㅇ 홍

낭

政

할안

5

- 吕폰।

运总

鱼育新

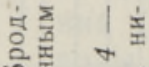

응 它递

的 5

임

토옹잉

0 舟

高

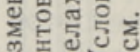

工舟》

पे

เ

究।

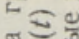

证要造

땐종

《읍 분

옹

5

은을

풀

送:

크을

은

है월충

흘 웅

똥이

占哭

5.

잉 동

○ 인

저유

藏

는

En

ज的

尊 =

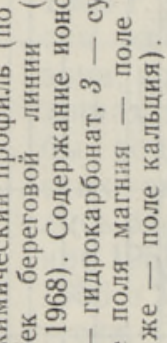

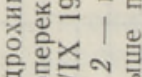

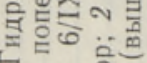

+즐

这 1 空

$\stackrel{+}{\mathbb{N}}$

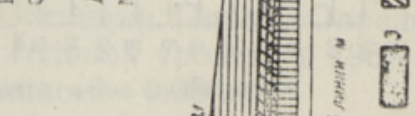

। ।

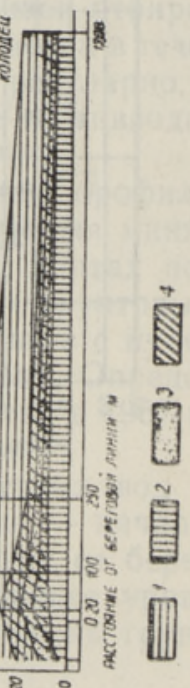


Летний минимум в 1966 и 1968 гг. наступил в июне, длился примерно две-три недели и был на $0,68-0,75$ м ниже среднего годового уровня. В 1967 г. ясновыраженного летнего минимума грунтовых вод не отмечалось; самый низкий уровень воды в июне оказался на $0,39-$ 0,47 н ниже среднего. В различные годы в июле или августе уровень грунтовых вод поднимался на $0,60-0,80 \mu$, но в следующем месяце он снова падал, а затем постепенно поднимался.

Осенний максимум в 1966 г. наступил в сентябре, а в 1967 и 1968 гг. в октябре, продолжался 25-30 дней и превыщал весенний на 0,200,30 м. Пройдя через максимум, уровень грунтовых вод резко падал на $0,60-0,70 \mu$, затем несколько раз испытывал кратковременный подъем и лишь в ноябре 1966 г. и в начале декабря 1967 и 1968 гг. начал постепенно понижаться, достигнув минимума в январе-феврале следуюшего года. Зимний минимум в 1966-1967 гг. был на 0,22$0,46 м$, а в $1967-1968$ гг. на $0,5 м$ выше летнего.

Годовая амплитуда колебаний уровня грунтовых вод в наблюдаемый период оставалась в пределах 0,96-1,32 м.

В течение трехлетнего периода наблюдений установлена явная зависимость между изменением гидрометеорологических условий и режимом грунтовых вод.

Слабовыраженный летний максимум в 1967 г. и более высокий по сравнению с другими годами уровень грунтовых вод были обусловлены высоким положением уровня моря в этом году. Вообще все сезонные колебания уровня воды в море, даже кратковременные подъемы и спады, явно отражались на уровне грунтовых вол. Особенно это было заметно в летние периоды (июль-август) (рис. 2).

На исследованном профиле атмосферные осадки не оказывали заметного влияния на уровенный режим грунтовых вод. Роль их как будто подавлялась морем. Например, в 1967 г. количество атмосферных осадков было примерно на 40 мм больше, чем в 1968 г., и на 40 мм меньше, чем в 1966 г., но средний годовой уровень моря превышал. этот показатель за предыдущий и последуюший годы на $0,18 \mu$, а средний годовой уровень грунтовых вод соответственно на $0,12-0,17 \mathrm{M}$.

Обычно ветры западного направления сопровождаются дождем и нагоном моря. На рис. 2 пики колебаний уровней грунтовых вод и моря более или менее совпадают, но амплитуды их колебаний отличаются. Подъем уровня грунтовых вод иногда превышает подъем уровня моря, особенно в скважинах, удаленных от береговой линии моря; разница тем значительнее, чем больше выпадает атмосферных осадков.

В результате постоянных наблюдений установлено, что в зависимости от гидрометеорологических условий на низком пологом берегу грунтовые воды движутся или в сторону моря, или в сторону суши. При низких уровнях моря поток грунтовых вод направлен в основном в море, а во время нагона - в противоположную сторону. При высоком уровне моря и при выпадении атмосферных осадков гпдравлический уклон фильтрационного потока между скважинами $3-5$ направлен к берегу, а между скважинами $1-2$ к морю (рис. 3).

Из менение химического состава грунтовых вод изучалось в трех наблюдательных скважинах и, кроме того, в колодце, расположенном на этом же профиле.примерно на расстоянии 1200 м от береговой линии.

Грунтовые воды, распространенные на территории Эстонии, имеют обыкновенно минерализацию $0,3-0,5$ 2/ и по своему химическому составу относятся главным образом к гидрокарбонатному магниевокальциевому типу (Верте, 1965; Каризе, 1966). 


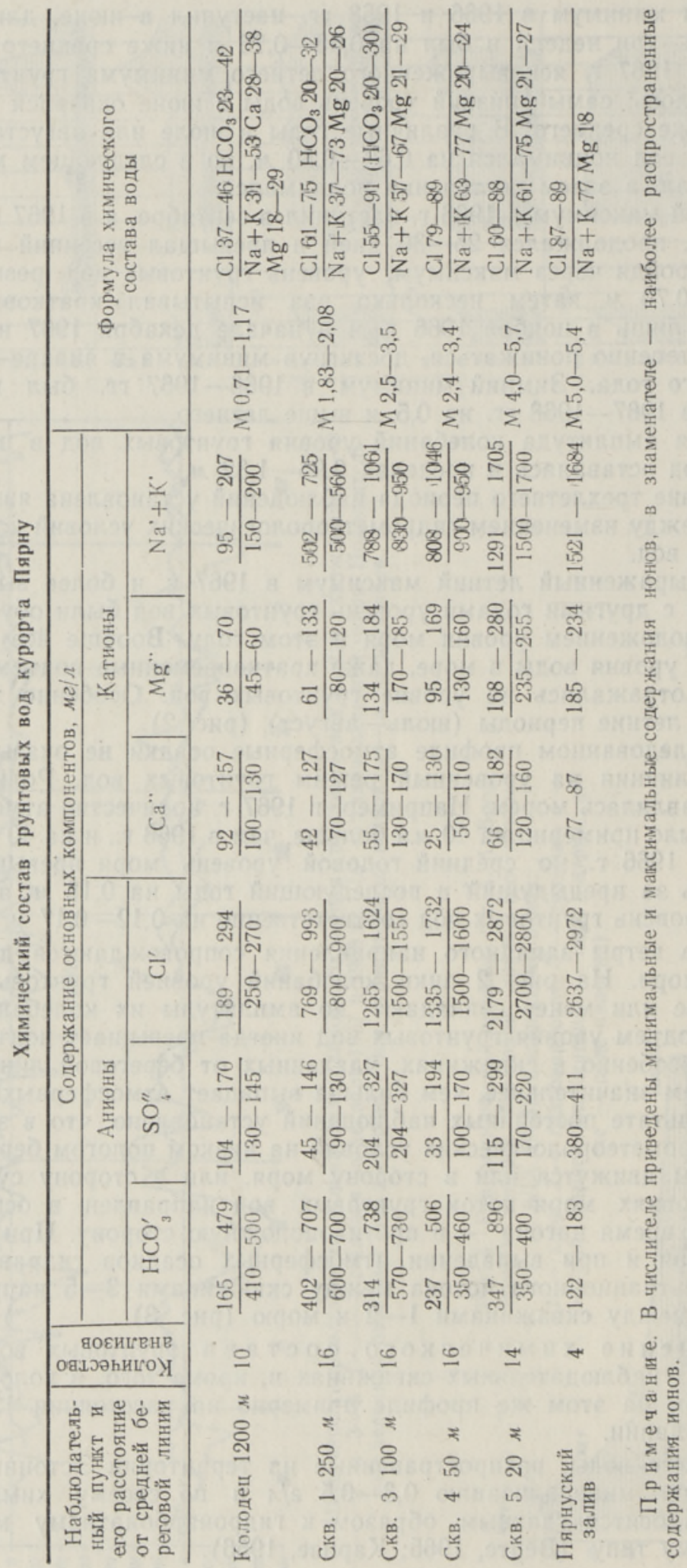


На берегу моря в наблюдательных скважинах под влиянием морской воды грунтовая вода была хлоридная магниево-натриевая, а на расстоянии $200 м$ от береговой линии переходила в гидрокарбонатно-хлоридную магниево-натриевую. Иногда в период максимального уровня грунтовых вод отмечалось увеличение содержания в ней гидрокарбонатов уже на расстоянии 100 м от береговой линии. Вода в наблюдаемом колодце была гидрокарбонатно-хлоридная магниево-натриево-кальциевая или магниево-кальциево-натриевая.

Минерализация воды постепенно уменьшалась по профилю от моря к суше от $4,0-5,7$ г/ $\Omega$ в скв. 5 до $1,83-2,08$ г/ $\Omega$ в скв. 1 и $0,71-1,17$ г/ в колодце (таблица).

Грунтовые воды в скв. 5 во время нагонов находились в непосредственном контакте с морской водой. Вследствие этого минерализация грунтовых вод в скв. 5 и морской воды была почти одинаковой, а гидрохимический тип сходным, только абсолютное количество основных компонентов различалось - в грунтовых водах было больше гидрокарбоната и меньше хлора и натрия (рис. 4).

С удалением от моря количество хлора и натрия в грунтовых водах уменьшалось, причем особенно резко на протяжении первых $200 \mu$ от средней береговой линии (рис. 4). Так. содержание хлор-иона уменьшилось в среднем от 2700 (скв. 5) до 800 ма/л (скв. 1). т. е. примерно на $950 \mathrm{~m} / \Omega$ на каждые $100 \mu$, а в пределах следуюших $1000 \wedge$ - только на 55 мг/л на 100 м. Отсюда следует, что область интенсивного смешения ионов вод различного химического состава простирается примерно на $250-300 м$ от береговой линии.

Хотя химический состав грунтовых вод в пределах одной скважины и был довольно постоянным (рис. 5), но все же определенную зависимость между изменением ее минерализашии и уровнем грунтовых вод можно отметить. В январе-феврале 1967 г., т. е. в период минимального уровня, когда почва была замерзшей и инфильтрация атмосферных осадков с поверхности отсутствовала, минерализация грунтовых вод возросла за счет увеличения содержания всех ионов, преимущественно ионов хлора, натрия и магния, на $0,50-0,602 / \Omega$, а в скв. 5 даже на 1,4 г/л, хотя гидрохимический тип воды остался прежним.

Согласно данным наблюдаемого колодца, во время мартовского половодья под влиянием талых инфильтрационных вод минерализация грунтовых вод уменышилась на 0,3 2/, , главным образом за счет уменьшения количества всех ионов. С апреля до августа минерализация воды в скважинах постепенно повысилась на $0,1-0,2$ г/л вследствие уменьшения атмосферного питания грунтовых вод и увеличения испарения в летнее время. Несмотря на некоторый рост содержания сульфатов, магния и хлора, гидрохимический тип воды не изменился.

Во время осенних дождей минерализация грунтовых вод снова понизилась на $0,10-0,20$ г/л и достигла минимума, по данным 1966 г., в ноябре-декабре. Годовая амплитуда колебания минерализации, не считая октября 1967 г., в прибрежной скв. 5 составила 1,7 г/л, в скв. 2-4 соответственно $0,4-0,5$ z/ $\Omega$ и в скв. 1 только 0,25 г/ $/$.

Следует отметить, что при нагоне осолоняющее действие морской воды на грунтовые воды незначительное. Во время нагона образуется подпор грунтовых вод, дренаж их задерживается, уровень повышается, а притекающая со стороны суши пресная вода перемешивается с солоноватыми прибрежными грунтовыми водами и опресняет их. Но при кратковременном затоплении морской водой береговой зоны минерализация грунтовых вод резко повышается. Так, в октябре 1967 г. после затопления морской водой устья всех скважин скачок минерализации воды в 
скв. $2-5$ составил $0,6-0,1$ г/ , в скв. 1 был равен $22 / \Omega$, а в колодце достиг даже 3 г/л. Одновременно изменился и химический состав вод, но уже к концу ноября минерализация воды уменьшилась и хлоридно-натриевый тип воды изменился на прежний.

Резюмируя изложенное выше, можно отметить следуюшее.

1. На морском берегу курорта Пярну уровенный режим грунтовых вод формируется как под влиянием колебания уровня моря, так и под действием атмосферных осадков. Поток грунтовых вод во время нагона направлен в основном в сторону суши, а при низком положении уровня моря - в сторону моря.

2. Наиболее интенсивное влияние морской воды на изменение химического состава грунтовых вод в прибрежно-морских песках установлено на расстоянии 200-300 м от береговой линии. Минерализация грунтовых вод при минимальном уровне повышается до максимальных значений, а с повышением уровня - понижается.

\title{
ЛИТЕРАТУРА
}

Вер те А. 1965. Основные черты гидрогеологического строения и формирования подземных вод Эстонского артезианского бассейна. Изв. АН ЭССР, сер. биол., 14, № 4 .

К а риз е В. 1966. Основные черты формирования состава вод четвертичных отложеннй Южной Әстонии. Изв. АН ЭССР, сер. физ.-матем, и техн. наук, 15, № 4.

\author{
Ннститут геологии \\ Академии наук Эстонской ССР
}

Поступила в редакцию

16/I 1974

Aino PILL

\section{PINNASEVEE TASEME KOIKUMISED JA MINERALISATSIOON - PARNU RANNAS}

Pärnu ranna liivades sõltub pinnasevee tase meretaseme kōikumisest ja sademetest. Mere kõrgseisu ajal liigub pinnasevesi mandri, madalseisu ajal ja rohkete sademete puhul aga mere poole.

Pinnasevee keemilise koostise ja taseme vahel esineb teatud seos. Madalseisu ajal on pinnasevee mineralisatsioon kõrgem ja kloriidne vesi ulatub kuni 200 meetrini rannajoonest, veetaseme tōustes langeb vee mineralisatsioon ja suureneb vesinikkarbonaatidesisaldus. Merevee môju pinnasevee keemilisele koostisele avaldub kõige intensiivsemalt kuni 200-300 meetrini keskmisest rannajoonest.

Aino PILL

\section{THE WATER LEVEL AND MINERALIZATION OF UNDERGROUND WATERS ON THE SEASHORE OF THE SEASIDE RESORT PÄRNU (ESTONIA)}

On the seashore of the seaside resort Pärnu, the water level of the underground waters is affected by the fluctuations of the level of the sea as well as by the action of precipitation.

A definite connexion is observed between the level of the underground waters and their chemical composition. At low water level, the degree of the mineralization is higher, and the chloride-containing water spreads to a distance of about $200 \mathrm{~m}$ from the shoreline. On the other hand, with a higher water level mineralization decreases, whereas the content of hydrocarbonates increases. The influence of the seawater upon the chemical composition of the underground waters is most intensive at a distance of up to $200 \ldots 300 \mathrm{~m}$ from the shoreline. 